\title{
Characteristics and management of HIV-I-infected pregnant women enrolled in a randomised trial: differences between Europe and the USA
}

\author{
Marie-Louise Newell*1, Sharon Huang2, Simona Fiore ${ }^{1}$, Claire Thorne ${ }^{1}$, \\ Laurent Mandelbrot ${ }^{3}$, John L Sullivan ${ }^{4}$, Robert Maupin ${ }^{5}$, Isaac Delke ${ }^{6}$, D \\ Heather Watts ${ }^{7}$, Richard D Gelber ${ }^{2}$, Coleen K Cunningham ${ }^{8}$ for the PACTG \\ 316 Study Team
}

\begin{abstract}
Address: ${ }^{1}$ Centre of Paediatric Epidemiology and Biostatistics, Institute of Child Health, University College London, UK, ${ }^{2}$ Centre for Biostatistics in AIDS Research, Harvard School of Public Health, Boston, USA, ${ }^{3}$ Service de Gynecologie-Obstetrique, APHP Hopital Louis Mourier, F-75701 Colombes, Universite Diderot, Paris 7, and Inserm, U822, IFR69, F-94276, France, ${ }^{4}$ Department of Pediatrics and Molecular Medicine, University of Massachusetts Medical School, Worcester, USA, ${ }^{5}$ Department of Obstetrics and Gynecology, Louisiana State University Health Sciences Center, New Orleans, USA, ${ }^{6}$ Department of Obstetrics and Gynecology, University of Florida College of Medicine, Jacksonville, USA, ${ }^{7}$ Pediatric, Adolescent, and Maternal AIDS Branch, National Institute of Child Health and Human Development, Bethesda, USA and ${ }^{8}$ Department of Pediatrics, Duke University Medical Center, Durham, USA
\end{abstract}

Email: Marie-Louise Newell* - m.newell@ich.ucl.ac.uk; Sharon Huang - sharon@sdac.harvard.edu; Simona Fiore - s.fiore@ich.ucl.ac.uk; Claire Thorne - c.thorne@ich.ucl.ac.uk; Laurent Mandelbrot - laurent.mandelbrot@lmr.aphp.fr;

John L Sullivan - john.sullivan@umassmed.edu; Robert Maupin - rmaupi@lsuhsc.edu; Isaac Delke - isaac.delke@jax.ufl.edu; D

Heather Watts - wattsh@exchange.nih.gov; Richard D Gelber - gelber@jimmy.harvard.edu;

Coleen K Cunningham - coleen.cunningham@duke.edu

* Corresponding author

Published: 20 June 2007

BMC Infectious Diseases 2007, 7:60 doi:10.1 186/147/-2334-7-60

This article is available from: http://www.biomedcentral.com/I47I-2334/7/60

(c) 2007 Newell et al; licensee BioMed Central Ltd.

This is an Open Access article distributed under the terms of the Creative Commons Attribution License (http://creativecommons.org/licenses/by/2.0), which permits unrestricted use, distribution, and reproduction in any medium, provided the original work is properly cited.

\begin{abstract}
Background: Rates of mother-to-child transmission of HIV-I (MTCT) have historically been lower in European than in American cohort studies, possibly due to differences in population characteristics. The Pediatric AIDS Clinical Trials Group Protocol (PACTG) 316 trial evaluated the effectiveness of the addition of intrapartum/neonatal nevirapine in reducing MTCT in women already receiving antiretroviral prophylaxis. Participation of large numbers of pregnant HIV-infected women from the US and Western Europe enrolling in the same clinical trial provided the opportunity to identify and explore differences in their characteristics and in the use of non-study interventions to reduce MTCT.
\end{abstract}

Methods: In this secondary analysis, 1350 women were categorized according to enrollment in centres in the USA $(n=978)$ or in Europe $(n=372)$. Factors associated with receipt of highly active antiretroviral therapy and with elective caesarean delivery were identified with logistic regression.

Results: In Europe, women enrolled were more likely to be white and those of black race were mainly born in Sub-Saharan Africa. Women in the US were younger and more likely to have previous pregnancies and miscarriages and a history of sexually transmitted infections.

More than $90 \%$ of women did not report symptoms of their HIV infection; however, more women from the US had symptoms (8\%), compared to women from Europe (4\%). Women in the US were 
less likely to have HIV RNA levels $<400$ copies/ml at delivery than women enrolling in Europe, and more likely to receive highly active antiretroviral therapy, and to start therapy earlier in pregnancy. The elective caesarean delivery rate in Europe was $61 \%$, significantly higher than that in the US (22\%). Overall, $1.48 \%$ of infants were infected and there was no significant difference in the rate of transmission between Europe and the US despite the different approaches to treatment and delivery.

Conclusion: These findings confirm that there are important historical differences between the HIV-infected pregnant populations in Western Europe and the USA, both in terms of the characteristics of the women and their obstetric and therapeutic management. Although highly active antiretroviral therapy predominates in pregnancy in both settings now, population differences are likely to remain.

\section{Trial registration: NCT00000869}

\section{Background}

Rates of mother-to-child transmission of HIV-1 (MTCT) have historically been lower in European than in American cohort studies [1-8]. It has been suggested that this was likely to be related to differences in population characteristics $[9,10]$. Although in the 1980s and early 1990s the HIV epidemic among pregnant women in Europe was mainly associated with injecting drug use (IDU) [11,12], since the mid-1990s there has been a shift towards heterosexually-acquired HIV, largely in women of sub-Saharan origin $[12,13]$. Generally, health care services and in particular antenatal care is readily available to these populations in Western Europe. In the USA, there has been a similar trend, with heterosexual acquisition overtaking IDU as the main transmission category among women with AIDS in 1995 [14]; in 2004, 78\% of HIV infections among women were due to heterosexual contact, $20 \%$ to IDU and $2 \%$ to other routes [14]. Differences in health care provision and standards of care may have led to differences between these two geographical regions in the availability and uptake of various interventions available for HIV infected pregnant women [15-19].

The PACTG 316 trial was a placebo-controlled randomised trial to evaluate the additional value of single dose nevirapine (sdNVP) at delivery in reducing MTCT in women already receiving antiretroviral prophylaxis [20]. The trial was initiated in the USA in 1997 and extended through collaboration with two large ongoing European perinatal cohort studies, the French Perinatal Cohort Study (ANRS 083) and the European Collaborative Study [21]. The trial was stopped prematurely in June 2000 after the results of a planned interim analysis indicated a lower than anticipated overall MTCT rate $(1.5 \%)$, without a significant difference between the sdNVP and the placebo arms [20].

We here take the opportunity to identify and explore differences in the characteristics of HIV infected pregnant women enrolling in the trial, and in the use of interventions to reduce MTCT between Europe and USA, in particular, the use of highly active antiretroviral therapy (HAART) and elective caesarean delivery.

\section{Methods}

The PACTG 316 trial was initiated in the United States (including Puerto Rico) in May, 1997. Between May 1997 and June 2000, centres collaborating in France, Italy, Spain, Sweden, UK, Belgium, Germany, Switzerland, Holland, Denmark, Bahamas and Brazil were invited to join the PACTG 316 trial. The methods of this randomized, blinded trial have been fully described elsewhere [20]. In brief, HIV-infected pregnant women were initially enrolled in the trial after 28 weeks of gestation (later reduced to 20 weeks), with written informed consent. They were randomised to receive either oral nevirapine (200 $\mathrm{mg}$ at onset of labour) or placebo; their infants received the same study drug (infant $2 \mathrm{mg} / \mathrm{kg}$ oral nevirapine or placebo) 48-72 hours after birth. All clinicians were encouraged to offer all HIV-infected pregnant women at least a regimen of prophylactic zidovudine monotherapy in line with the ACTG 076 protocol [22]. Women were allowed to receive any combination of licensed antiretroviral drugs in pregnancy as prescribed by their clinician, with the exception of non-nucleoside reverse transcriptase inhibitors.

In all participating centres, HIV-infected women were systematically identified during pregnancy, according to local practice. At enrolment, baseline information including socio-demographic characteristics, obstetric history, history of and current use of antiretroviral therapy (ART), results from screening for sexually transmitted infections (STI) (gonorrhea, chlamydia, human papilloma virus, herpes simplex, syphilis and trichomonas vaginalis) and clinical history were collected using standardized forms. Clinical and laboratory evaluations, including CD4 lymphocyte count and HIV RNA quantification were carried 
out at enrolment, delivery and post-partum. CD4 counts and viral load measurements were carried out locally in laboratories which were certified by ACTG or other regional quality assurance programme. Infants had clinical and laboratory information collected at birth, and subsequently according to the protocol.

\section{Definitions}

In this analysis, we compared all mother-child pairs enrolled in the European centres participating in the trial with those enrolled in the sites in the USA and Puerto Rico. Mode of acquisition of HIV infection was assessed on the basis of self-report; no illicit drug screening was carried out. Gestational age was estimated with ultrasound performed at less than 20 weeks gestation or use of date of last menstrual period that corresponded with uterine size. Caesarean deliveries taking place before the onset of labour and before rupture of membranes were classified as elective caesarean deliveries, with all other caesarean deliveries classified as emergency procedures regardless of indication. Low birth weight was defined as birth weight $<2500 \mathrm{~g}$. Classification of type of antenatal ART was on the basis of the most potent therapy received. ART was classified as monotherapy if a single nucleoside was administered at a time, as dual therapy if any two nucleosides were administered and as HAART if a protease inhibitor plus two other drugs (excluding NNRTIs as this was an exclusion criteria for the trial) were administered. Undetectable viral load was defined as having HIV RNA levels below 400 copies/ml. Symptomatic HIV disease was defined as being in the Centers for Disease Control (CDC) disease category B and $\mathrm{C}$.

\section{Statistical analysis}

For univariate comparisons among women between Europe and USA, two-sided tests were performed using $\chi^{2}$ test or Fisher exact tests for discrete outcomes, and Wilcoxon test for continuous outcomes. For the multivariate comparisons, logistic regression analysis was used to obtain odds ratios (OR), adjusted odds ratios (AOR) and 95\% confidence intervals (95\% CI). Statistical software SAS (SAS Institute, Cary, North Carolina, USA) was used for the statistical analysis.

\section{Results}

A total of 1350 women enrolled in the trial had delivered by the time the trial was stopped, 978 (72\%) from the USA and 372 (28\%) from Europe. Table 1 presents sociodemographic and most likely mode of acquisition of HIV infection by continent. There was a significantly higher proportion of white women in the European centres than in the USA. Nearly half of the women from European centres were black; most had been born in sub-Saharan Africa. As Table 1 shows, there were significant differences between the two populations with regard to history of reproductive health, with women in the USA having a higher prevalence of previous miscarriages (28\% versus $13 \%$ ) and higher parity compared to those in Europe, who had a higher prevalence of history of pregnancy termination ( $48 \%$ versus $27 \%$ in the USA). Substantially and significantly fewer women enrolling in Europe had a history of STI compared with those in the USA.

In terms of HIV-related characteristics, although there were no significant differences between continents with regard to immunological status at study entry and at delivery, women from the USA were more likely to have symptomatic HIV disease (Table 2). Very similar proportions in the two settings had HIV RNA levels below 400 copies/ml at study entry; however, by the time of delivery there was a significant difference between geographic areas, with fewer women in the US having HIV RNA below 400 copies/ml and an overall higher median in the US versus Europe. In a sub-analysis of the 259 women from European and the 539 women from USA sites who had been diagnosed with HIV infection prior to their current pregnancy, almost identical proportions (182/259, 70\% and 357/539, 66\%) were already receiving ART at enrolment. Among the 606 women in the USA who started ART in pregnancy, the median gestational age at initiation was 18 weeks (range, 14-25 weeks), substantially earlier than the median of 27 weeks (range 18-32) among the 190 women in Europe starting therapy antenatally.

Median gestational age at delivery was 38.4 weeks (37.3$39.6)$ and 38.1 weeks (37.1-39.0), and median birth weight was $3077 \mathrm{~g}$ and $3020 \mathrm{~g}$ in the USA and Europe, respectively. The prevalence of low birth weight was similar in both continents, at $12 \%$ in the US $(n=122)$ and $14 \%$ in Europe $(n=54)$. Mode of delivery varied significantly by geographic area $(\mathrm{p}<0.0001)$. In the USA, the elective caesarean delivery rate was $22 \%(n=212)$, the emergency caesarean delivery rate was $17 \%(n=169)$ and the vaginal delivery rate was $61 \%(n=597)$; respective rates in Europe were 61\% $(n=228), 18 \%(n=65)$ and $21 \%(n=79)$.

Subsequent analyses focused on geographic differences in the use of HAART in pregnancy and of elective caesarean delivery. Table 3 presents the results of univariable and multivariable logistic regression analyses to identify factors associated with likelihood of receiving HAART in pregnancy. Univariably, geographic area, low CD4 count and undetectable viral load at entry and at delivery were associated with receipt of HAART. In analyses adjusting for ethnicity, mode of delivery and immunological and virological status, women from the USA were nearly twice as likely to receive HAART as women from Europe, whilst those with CD4 counts $\geq 400$ cells/ml and detectable viral load at trial entry were significantly less likely to receive 
Table I: Characteristics of HIV-infected pregnant women in PACTG 316, USA versus Europe

\begin{tabular}{|c|c|c|c|c|}
\hline Characteristics & USA & Europe & Total & p-value* \\
\hline Total mothers delivered & 978 & 372 & 1350 & \\
\hline Median age: entry (IQR) & $27.2(22.9-31.8)$ & $30(26.9-34)$ & $28.1(23.9-32.4)$ & $<0.0001$ \\
\hline Ethnicity & & & & $<0.0001$ \\
\hline White & $119(12 \%)$ & $190(51 \%)$ & $309(23 \%)$ & \\
\hline Black & $621(64 \%)$ & $172(46 \%)$ & 793 (59\%) & \\
\hline Hispanic & $223(23 \%)$ & $8(2 \%)$ & $231(17 \%)$ & \\
\hline Other & $15(1.5 \%)$ & $2(0.5 \%)$ & $17(1 \%)$ & \\
\hline Parity & & & & 0.0001 \\
\hline $0-1$ & 161 (17\%) & $80(22 \%)$ & $24 \mid(18 \%)$ & \\
\hline $2-3$ & $399(41 \%)$ & $168(45 \%)$ & $567(42 \%)$ & \\
\hline $4-5$ & 267 (27\%) & $97(26 \%)$ & $364(27 \%)$ & \\
\hline$\geq 6$ & $15 \mid(15 \%)$ & $27(7 \%)$ & $178(13 \%)$ & \\
\hline Previous miscarriages & & & & $<0.0001$ \\
\hline 0 & 707 (72\%) & $325(87 \%)$ & $1032(76 \%)$ & \\
\hline $1-2$ & $247(25 \%)$ & $44(12 \%)$ & 291 (22\%) & \\
\hline $3-6$ & $24(2.5 \%)$ & $3(1 \%)$ & $27(2 \%)$ & \\
\hline Previous terminations & & & & $<0.0001$ \\
\hline 0 & $710(73 \%)$ & $192(52 \%)$ & 902 (67\%) & \\
\hline $1-2$ & $220(22 \%)$ & $149(40 \%)$ & $369(27 \%)$ & \\
\hline $3-4$ & $41(4 \%)$ & $28(7 \%)$ & $69(5 \%)$ & \\
\hline $5-12$ & $7(1 \%)$ & $3(1 \%)$ & $10(1 \%)$ & \\
\hline Timing of HIV diagnosis & & & & $<0.0001$ \\
\hline Pre-pregnancy & $539(55 \%)$ & $259(70 \%)$ & $798(59 \%)$ & \\
\hline Antenatal & $439(45 \%)$ & $112(30 \%)$ & $55 I(4 I \%)$ & \\
\hline \multicolumn{5}{|l|}{ Mode of acquisition\# } \\
\hline Sexual with HIV at risk & $336(34 \%)$ & $44(12 \%)$ & $380(28 \%)$ & $<0.0001$ \\
\hline Sexual with HIV positive & $214(22 \%)$ & $105(28 \%)$ & $319(24 \%)$ & 0.0623 \\
\hline Sexual with HIV unknown & $716(73 \%)$ & 162 (44\%) & $878(65 \%)$ & $<0.0001$ \\
\hline Current IDU & $12(1 \%)$ & II (3\%) & $23(2 \%)$ & 0.0331 \\
\hline Previous IDU & $68(7 \%)$ & $35(9 \%)$ & $103(8 \%)$ & 0.1340 \\
\hline Blood transfusion & $20(2 \%)$ & $7(2 \%)$ & $27(2 \%)$ & 0.9999 \\
\hline Occupational risk & $22(2 \%)$ & $3(1 \%)$ & $25(2 \%)$ & 0.1108 \\
\hline Other risk factor & $44(4 \%)$ & $8(2 \%)$ & $52(4 \%)$ & $<0.0001$ \\
\hline Unknown risk factor & $47(5 \%)$ & $46(12 \%)$ & $93(7 \%)$ & 0.0401 \\
\hline STD history & & & & $<0.0001$ \\
\hline Yes & $280(29 \%)$ & $19(5 \%)$ & $299(22 \%)$ & \\
\hline No & $450(46 \%)$ & $353(95 \%)$ & $803(60 \%)$ & \\
\hline Unknown & $248(25 \%)$ & $0(0)$ & $248(18 \%)$ & \\
\hline
\end{tabular}

\# Some women reported multiple risk factors

* for the difference USA versus Europe

HAART in pregnancy. Stratified analyses for the two geographic areas identified the same risk factors, with odds ratios of similar magnitudes.

In addition to use of antiretroviral drugs in pregnancy and avoidance of breastfeeding, elective caesarean delivery is the other key PMTCT intervention. Further logistic regressions were therefore carried out for likelihood of having an elective caesarean versus other delivery modes (emergency caesarean or vaginal delivery) (Table 4). Delivery in centres in the USA was associated with an adjusted $82 \%$ reduced odds of elective caesarean delivery compared with delivery in Europe. Black women were 33\% less likely to deliver by elective caesarean than white women, and those receiving two or more antiretroviral drugs antenatally were less likely to have an elective caesarean delivery compared with women receiving monotherapy or no ART (Table 4). As there were distinct differences between the continents regarding many of these explanatory variables (Tables 1 and 2), stratified analyses were carried out for each geographic area separately. Among the women from the USA, none of the explanatory variables in Table 3 were associated with elective caesarean delivery univariably [data not shown]. In Europe, black versus white ethnicity was associated with a reduced likelihood of elective caesarean, with borderline significance (AOR 0.65, 95\% CI $0.42-0.99, \mathrm{p}=0.048$ ), and dual therapy and HAART with around a two-thirds reduced likelihood of elective 
Table 2: Characteristics of HIV infected pregnant women, USA versus Europe: disease progression and treatment

\begin{tabular}{|c|c|c|c|c|}
\hline Characteristic & USA & Europe & Overall & P-value \\
\hline Median CD4 count: entry (IQR) & $437(293-600)$ & $420(299-568)$ & $430(294-592)$ & 0.6958 \\
\hline$<200$ cells per $\mathrm{ml}$ & $124(13 \%)$ & $37(10 \%)$ & $161(12 \%)$ & \\
\hline $200-499$ & $294(30 \%)$ & 132 (35\%) & $426(32 \%)$ & \\
\hline$\geq 500$ & $560(57 \%)$ & $203(55 \%)$ & $763(57 \%)$ & \\
\hline Median HIV RNA: entry (IQR) & $58 \mid(274-3635)$ & $700(200-4740)$ & $594(243-3845)$ & 0.1225 \\
\hline$\leq 400$ copies $/ \mathrm{ml}$ & $424(43 \%)$ & $142(38 \%)$ & $566(42 \%)$ & \\
\hline $400-2,499$ & $252(26 \%)$ & $92(24 \%)$ & $344(25 \%)$ & \\
\hline $2,500-10,000$ & $143(15 \%)$ & $62(17 \%)$ & 205 (15\%) & \\
\hline$>10,000$ & $138(14 \%)$ & $57(15 \%)$ & 195 (14\%) & \\
\hline Median CD4 count: delivery (IQR) & $480(308-658)$ & $444(320-632)$ & $469(310-653)$ & 0.6849 \\
\hline$<200$ cells $/ \mathrm{ml}$ & $103(12 \%)$ & $26(8 \%)$ & $129(11 \%)$ & \\
\hline $200-499$ & $233(27 \%)$ & $109(34 \%)$ & $342(29 \%)$ & \\
\hline$\geq 500$ & $531(61 \%)$ & $187(58 \%)$ & $718(60 \%)$ & \\
\hline Median HIV RNA: delivery (IQR) & $405(237-2638)$ & $200(68-1300)$ & $400(200-2300)$ & 0.0001 \\
\hline$\leq 400$ copies $/ \mathrm{ml}$ & $450(50 \%)$ & $176(64 \%)$ & $626(53 \%)$ & \\
\hline $400-2,499$ & $220(24 \%)$ & $49(18 \%)$ & $269(23 \%)$ & \\
\hline $2,500-10,000$ & $115(13 \%)$ & $36(14 \%)$ & 151 (13\%) & \\
\hline$>10,000$ & $116(13 \%)$ & $16(6 \%)$ & $132(11 \%)$ & \\
\hline Maternal ARV use & & & & $<0.0001$ \\
\hline HAART & $448(46 \%)$ & $119(32 \%)$ & 567 (42\%) & \\
\hline Dual therapy & $342(35 \%)$ & $132(35 \%)$ & $474(35 \%)$ & \\
\hline Monotherapy & $182(19 \%)$ & $119(32 \%)$ & $301(22 \%)$ & \\
\hline No ARV & $6(0.6 \%)$ & $2(0.5 \%)$ & $8(0.6 \%)$ & \\
\hline Timing of ARV initiation & & & & 0.0001 \\
\hline Pre-pregnancy & $357(37 \%)$ & $182(49 \%)$ & $539(40 \%)$ & \\
\hline During pregnancy & $606(63 \%)$ & $190(51 \%)$ & $796(60 \%)$ & \\
\hline Symptomatic HIV disease at entry & & & & 0.0194 \\
\hline Yes & $74(8 \%)$ & $15(4 \%)$ & $89(7 \%)$ & \\
\hline No & $904(92 \%)$ & 357 (96\%) & $126 \mid(93 \%)$ & \\
\hline
\end{tabular}

caesarean versus no therapy or monotherapy (AORs 0.35 [0.21-0.60] $\mathrm{p}<0.0001 ; 0.41$ [0.24-0.72] $\mathrm{p}=0.0015$ respectively).

The primary outcome measure of the PACTG 316 trial was detection of HIV infection in the infants. Overall there was a very low rate of MTCT at $1.48 \%$ [95\% CI 0.91-2.28] (20 vertical transmissions; USA $1.64 \%$ [95\% CI $0.94-2.64]$ and Europe $1.08 \%$ [0.29-2.73]).

\section{Discussion}

There were distinct differences between the HIV-infected pregnant women enrolling in the PACTG 316 trial in the USA (accounting for nearly three-quarters of the total mother-child pairs in the trial) compared with the European centres. Black women of African-American ethnicity predominated in the US setting, with a further quarter of the women enrolling of Hispanic ethnicity, and only $12 \%$ being non-Hispanic white. Those recruited in Europe were almost equally divided between white European and nonwhite women, the vast majority of whom were of African origin who had arrived in Europe as asylum-seekers, refugees or migrants. These ethnic patterns are consistent with what is known about the epidemiology of HIV infection in pregnancy in the USA and in Europe $[13,16,23]$.
Substantially more women from the European sites had been diagnosed with HIV prior to their current pregnancy than in the USA. Today, most identified HIV-infected women of child-bearing age are most likely diagnosed either as a result of antenatal testing or through more targeted testing of specific risk groups, such as injecting drug users or attenders of STD clinics. Parity was somewhat higher among the US women. Although there was a significantly higher prevalence of active IDU in Europe, this was only 3\% in this setting. On the basis of these findings, the lower ascertainment of infection status among the US women before entry may reflect poorer access to or uptake of antenatal HIV testing in prior pregnancies or of HIV testing outside antenatal care, or alternatively, the possibility that the women from the USA acquired their HIV infection more recently (i.e. since a previous pregnancy), which is consistent with their younger age compared with the women from European sites, and their somewhat higher CD4 count at entry.

In terms of reproductive health, the HIV-infected women in the USA had a significantly higher prevalence of previous miscarriages than in Europe, double that in Europe, which may reflect a variety of factors including possible geographic/cultural differences with regard to reporting 
Table 3: Factors associated with antenatal HAART use

\begin{tabular}{|c|c|c|c|c|}
\hline & $\mathbf{N}(\%)$ & OR $(95 \% \mathrm{Cl})$ & AOR $(95 \% \mathrm{Cl})$ & p-value \\
\hline \multicolumn{5}{|l|}{ Ethnicity } \\
\hline White & $309(23)$ & 1.0 & 1.0 & \\
\hline Black & $793(59)$ & $1.06(0.82,1.39)$ & $0.84(0.62,1.13)$ & 0.2470 \\
\hline Other & $248(18)$ & $1.15(0.82,1.62)$ & $0.96(0.66,1.39)$ & 0.8374 \\
\hline \multicolumn{5}{|l|}{ Geographic area } \\
\hline Europe & $372(28)$ & 1.0 & 1.0 & \\
\hline USA & $978(72)$ & $1.79(1.39,2.30)$ & $1.82(1.40,2.38)$ & $<0.0001$ \\
\hline \multicolumn{5}{|l|}{ Mode of delivery } \\
\hline Vaginal delivery or non-elective caesarean & $910(67)$ & 1.0 & 1.0 & \\
\hline Elective caesarean & $440(33)$ & $0.80(0.64,1.01)$ & $0.99(0.76,1.28)$ & 0.9366 \\
\hline \multicolumn{5}{|l|}{ CD4 count (entry) } \\
\hline$<400$ cells per $\mathrm{ml}$ & $586(43)$ & 1.0 & 1.0 & \\
\hline$\geq 400$ cells per $\mathrm{ml}$ & $764(57)$ & $0.43(0.35,0.54)$ & $0.36(0.28,0.46)$ & $<0.0001$ \\
\hline \multicolumn{5}{|l|}{ CD4 count (delivery) } \\
\hline$<400$ cells per $\mathrm{ml}$ & $543(40)$ & 1.0 & 1.0 & \\
\hline$\geq 400$ cells per $\mathrm{ml}$ & $807(60)$ & $0.49(0.40,0.62)$ & $0.76(0.56,1.03)$ & 0.0757 \\
\hline \multicolumn{5}{|l|}{ Viral load (entry) } \\
\hline Undetectable & $570(44)$ & 1.00 & 1.0 & \\
\hline Detectable & $740(56)$ & $0.58(0.46,0.72)$ & $0.48(0.38,0.61)$ & $<0.0001$ \\
\hline \multicolumn{5}{|l|}{ Viral load (delivery) } \\
\hline Undetectable & $626(53)$ & 1.0 & 1.0 & \\
\hline Detectable & $555(47)$ & $0.79(0.62,0.99)$ & $0.97(0.7 \mathrm{I}, \mathrm{I} .3 \mathrm{I})$ & 0.8197 \\
\hline
\end{tabular}

Table 4: Factors associated with likelihood of delivery by elective caesarean

\begin{tabular}{|c|c|c|c|c|}
\hline & $\mathbf{N}(\%)$ & OR (95\% Cl) & AOR (95\% Cl) & p-value \\
\hline \multicolumn{5}{|l|}{ Ethnicity } \\
\hline White & $309(23)$ & 1.0 & 1.0 & \\
\hline Black & $793(59)$ & $0.4 \mathrm{I}(0.3 \mathrm{I}, 0.53)$ & $0.67(0.49,0.91)$ & 0.0107 \\
\hline Other & $248(18)$ & $0.40(0.28,0.57)$ & $0.89(0.60,1.32)$ & 0.5490 \\
\hline \multicolumn{5}{|l|}{ Geographic area } \\
\hline Europe & $372(28)$ & 1.0 & 1.0 & \\
\hline USA & $978(72)$ & $0.18(0.14,0.23)$ & $0.18(0.14,0.24)$ & 0.0001 \\
\hline \multicolumn{5}{|l|}{ Antenatal ART } \\
\hline None/monotherapy & $309(23)$ & 1.0 & 1.0 & \\
\hline Dual therapy & $474(35)$ & $0.5 I(0.38,0.69)$ & $0.57(0.41,0.78)$ & 0.0006 \\
\hline HAART & $567(42)$ & $0.54(0.4 \mathrm{I}, 0.72)$ & $0.70(0.52,0.96)$ & 0.0263 \\
\hline \multicolumn{5}{|l|}{ CD4 count (entry) } \\
\hline$<400$ cells per $\mathrm{ml}$ & $586(43)$ & 1.0 & 1.0 & \\
\hline$\geq 400$ cells per $\mathrm{ml}$ & $764(57)$ & $1.06(0.84,1.33)$ & $1.08(0.84,1.39)$ & $0.537 \mid$ \\
\hline \multicolumn{5}{|l|}{ CD4 count (delivery) } \\
\hline$<400$ cells per $\mathrm{ml}$ & $543(40)$ & 1.0 & 1.0 & \\
\hline$\geq 400$ cells per $\mathrm{ml}$ & $807(60)$ & $1.04(0.83,1.31)$ & $1.10(0.86,1.42)$ & 0.4486 \\
\hline \multicolumn{5}{|l|}{ Viral load (entry) } \\
\hline Undetectable & $570(44)$ & 1.00 & 1.0 & \\
\hline Detectable & $740(56)$ & $0.97(0.77,1.23)$ & $0.83(0.65,1.07)$ & $0.157 \mid$ \\
\hline \multicolumn{5}{|l|}{ Viral load (delivery) } \\
\hline Undetectable & $626(53)$ & 1.0 & 1.0 & \\
\hline Detectable & $555(47)$ & $0.82(0.64,1.05)$ & $0.90(0.69,1.17)$ & 0.4308 \\
\hline
\end{tabular}


prior miscarriage as this was a self-reported variable. Although the women recruited in the US were younger than those enrolled in Europe, they had a higher parity than their European counterparts, whilst women from Europe had a significantly higher pregnancy termination rate; these findings may not only reflect cultural differences, but also access to reproductive care services [24].

The PACTG 316 trial spanned an important and dynamic era with regard to use of ART in pregnancy, both for maternal health and for preventing MTCT. Our findings reflect regional differences in use of combination ART, with more rapid uptake in the USA than in Europe $[19,25,26]$. In the Women and Infants Transmission Study, based in the USA and Puerto Rico, half of the pregnant women enrolled by 1998 were receiving HAART, increasing to more than $60 \%$ in $1999-2000$ [27]. In Europe, although there was a steadily increasing uptake of combination therapy in pregnancy, in the absence of a randomised trial to show the efficacy of HAART in prevention of MTCT, some clinicians showed caution regarding prescribing HAART for women without symptomatic HIV disease, preferring to continue using the combination of zidovudine monotherapy according to the 076 regimen, elective caesarean delivery and avoidance of breastfeeding [28-31].

These parallel situations are apparent in the geographic differences seen here, with significantly more HAART use in the USA versus more monotherapy use in Europe. However, these differences are largely historical, and HAART now predominates in the treatment of pregnant women in Europe [32,33]. A fifth of women in Europe received the dual combination of zidovudine and lamivudine in pregnancy (data not shown); this partly reflects ongoing research in France at the time [34]. Furthermore, the lower prevalence of HAART use in European women may also reflect the non-eligibility of those women on HAART due to prior or current use of NVP-containing HAART, which was a popular regimen in Europe at the time [28]. Although the enrolled women from the US and Europe had similar CD4 counts and viral loads at entry, the US women had double the prevalence of symptomatic disease at entry (although this was low overall in both areas) and were less likely to have been diagnosed with HIV infection before the current pregnancy or to already be on ART at the time they became pregnant. Overall, $60 \%$ of women started ART for the first time in pregnancy and antenatal ART initiation was significantly earlier in the US than in Europe (18 weeks versus 27 weeks), probably reflecting timing of HIV diagnosis and/or management differences. By the time of delivery, although the two geographic groups remained immunologically similar, women from the USA were significantly less likely to have undetectable viral loads at delivery compared with women delivering in Europe, despite more women from the US receiving earlier and/or more potent ART. However, MTCT rates were similar between continents. In a previous analysis focused on women in the US sites of the PACTG 316 trial, black women (accounting for nearly two-thirds of the women enrolled) were significantly less likely to achieve undetectable viral loads by delivery than white women [35].

There was a considerably lower elective caesarean rate among the women delivering in the USA than in Europe, at $22 \%$ versus $61 \%$. None of the explanatory variables (ethnicity, ART, maternal CD4 count or viral load) predicted likelihood of elective caesarean delivery among women from the USA. This is consistent with an individualised approach to elective caesarean delivery in this setting among HIV-infected women, with those with obstetric indications for elective caesarean most likely to constitute the majority of the elective caesarean group [36,37].

In Europe, guidelines current during the trial recommended universal offer of elective caesarean delivery to prevent MTCT [38-40]. However, as indicated by the subanalysis of European women, receipt of HAART was associated with a significantly lower likelihood of having an elective caesarean delivery. This reflects the growing uncertainty from this time of the added benefit of elective caesarean delivery for women with undetectable plasma HIV RNA loads, and specifically concerns that the potential benefits in terms of reduced MTCT risk may be outweighed by the costs, such as the increased risk of postpartum complications and greater burden on health care services associated with elective caesarean delivery. This lack of consensus has continued in the absence of a definitive answer, with current policy and practice regarding mode of delivery varying considerably across Europe, although an increasing number of policies now recommend offering a vaginal delivery to women on successful HAART with undetectable viral load [41].

Concerns exist regarding the generalizability of results from HIV clinical trials, particularly those with stringent inclusion and exclusion criteria [42-44]. The PACTG 316 trial was designed with broad inclusion criteria, although the exclusion criteria of previous NNRTI-use may limit the generalizability of specific results here, as discussed above.

\section{Conclusion}

These findings confirm that there are important historical differences between the HIV-infected pregnant populations in Western Europe and the USA, both in terms of the characteristics of the women and their obstetric and therapeutic management. Although the therapeutic management of pregnant HIV-infected women is now more 
uniform between the continents, with the predominance of HAART initiated from before or during pregnancy, significant population differences are likely to remain. This is of importance in interpreting results from previous research and in the design of future studies.

\section{Abbreviations}

ART Antiretroviral therapy

HAART Highly active antiretroviral therapy

HIV Human immunodeficiency virus

IDU Injecting drug user

MTCT Mother-to-child transmission

PMTCT Prevention of mother-to-child transmission

RNA Ribonucleic acid

sdNVP Single dose nevirapine

\section{Competing interests}

The author(s) declare that they have no competing interests.

\section{Authors' contributions}

CKC, RDG, JS and MLN contributed to study concept and design. CKC, RDG, MLN, SF, LM, JS, RM, ID, DHW were involved in the acquisition of data. MLN, SF and CT drafted the manuscript. SH performed the statistical analyses. All authors critically revised the manuscript for important intellectual content. All authors read and approved the final manuscript.

\section{Acknowledgements}

Sources of support

Supported by the Pediatric AIDS Clinical Trials Group of the National Institute of Allergy and Infectious Diseases and the Pediatric/Perinatal AIDS Clinical Trials Group of the National Institute of Child Health and Human Development, National Institutes of Health, the Agence Nationale de Recherches sur le SIDA (ANRS 083) and Boehringer Ingelheim (France); and the European Commission (QLRT-1999-30002) and the Medical Research Council (UK). This analysis was supported by the Statistical and Data Analysis Centerof the AIDS Clinical Trials Group, under the National Institute of Allergy and Infectious Diseases cooperative agreement No. U0 I Al4IIIO.

The PACTG 316 Study Team includes Alejandro Dorenbaum, MD, (University of California, San Francisco, Ca), Lynne Mofenson MD (National Institute of Child Health and Human Development, Bethesda, Md), Mary Culnane, MS, CRNP, (National Institute of Allergy and Infectious Disease, Rockville, Md), Brigitte Bazin, MD (ANRS, Villejuif, France), Paula Britto, MS and Rajalakshm Balasubramanian Sc.D (Statistical and Data Analysis Center, Harvard School of Public Health, Boston, Mass), Yvonne Bryson, MD (UCLA School of Medicine, Los Angeles, Calif), Bethann Cunningham-
Schrader, MS and Kathleen A. Kaiser, AAS, COTA (Frontier Science and Technology Research Foundation, Buffalo, NY), Scharla Estep, MS, RPh (NIAID, Bethesda, Md), Maria Gigliotti, MS (Boehringer Ingelheim), Adolfo Gonzalez-Garcia, MD (University of Miami), Mark Mirochnick, MD (Boston University, Boston, Mass), Claire Rekacewicz, MD and Jean Francois Delfraissy, MD (ARNS, Villejuif, France), Maureen Shannon, MS, FNP (San Francisco General Hospital, San Francisco, Calif), Savita Pahwa (University of Miami) and John L. Sullivan, MD (University of Massachusetts, Worcester, Mass). The European Collaborative Study (ECS) includes investigators and study sites throughout Europe (listed below). Collaborating investigators include PACTG: Dr Beverly E. Sha and Ruth M. Davis, RN (Rush-Presbyterian/St Lukes, Chicago, III), Dr Arlene D. Bardeguez and Jocelyn Grandchamp, RN (University of Medicine and Dentistry of NJ), Lisa Melton and Audra Deveikis (Long Beach Memorial), Dr William T. Shearer and Dr Hunter A. Hammill (Baylor College of Medicine), Dr Ram Yogev and Donna Stanislawski (Children's Memorial and Prentice Women's Hospital), Dr Charles D. Mitchell and Patricia Bryan, RN (University of Miami), Dr William Borkowsky and Maryann Minter, RN (Bellevue Hospital), Dr Diane Wara and Maureen Shannon, RN, MS FNP, CNM (UCSF Moffitt Hospital), Dr Diane Wara and Dr Karen Beckerman (San Francisco General), Dr Ana Puga and Dr Winston Bliss (Children's Diagnostic and Treatment Center), Dr Jane Pitt and Dr Gina Brown (Columbia University), Dr Gary Kaufman and Laureen Katz, RN (Boston Medical Center), Andrew D. Hull and Stephen A. Spector (UCSD Medical Center), Dr Elizabeth Livingston and Lori Ferguson, RN (Duke University), Dr Mobeen Rathore and Dr Isaac Delke (University of Florida Health Sciences Center), Dr Wilma Lim and Betsy Pitkin, RN (University of North Carolina at Chapel Hill), Dr Jorge Gandia and Dr Eleanor Jimenez (San Juan City Hospital), Dr Sohail Rana and Marilyn Dennis (Howard University Hospital), Dr Alice Stek and Dr Andrea Kovacs (University of Southern California), Dr Elizabeth J. McFarland and Carol Salbenblatt, RN (Children's Hospital), Dr Myron J. Levin and Dr Adriana Weinberg (Denver Medical Center), Susan Laverty, RN, and Dr Geoffrey A. Weinberg (University of Rochester), Dr Hannah Gay and Netta Boudreaux, RN (University of Mississippi Medical Center), Dr Susanne R. Lavoie and Tima Y. Smith, RN (Medical College of Virginia), Dr Edwin Thorpe and Ms Nina Sublette (Regional Medical Center), Dr Dan Lancaster and Dr Debra Terry (Methodist Hospital Central), Dr Gregory J. Wilson and Peggy Bender, FNP (Vanderbilt University Medical Center), I. Heyer, RN, BSN, and Dr L. Lugo (University of Puerto Rico), Harold W. Lischner, MSN, and Kelly R. Hassey, MSN, CRNP (St Christopher's Hospital for Children), Deb Goldman, ARNP, and Dr Jane Hitti (Children's Hospital and Medical Center), Dr Robert Maupin and Dr Thomas Alchediak (Tulane University Hospital), Dr Katherine Luzuriaga and Sheila Noone, RN, PhD (University of Massachusetts Medical School), Dr Winston Campbell (University of Connecticut), Gail Karas, RN, and Dr Juan C. Salazar (Connecticut Children's Medical Center), Dr George Wendel and Dr Janet Squires (Children's Medical Center), Dr Theodore Jones and Dr Ellen Moore (Children's Hospital of Michigan), Dr Jaime Deville and Maryanne Dillon, BSN (University of California Medical Center), Dr Ruth Tuomala (Brigham and Women's Hospital), Dr Sandra Burchett (Children's Hospital), Dr John Farley and Barbara Davis, RN, MEd (University of Maryland), Dr Kenneth Rich and Dr Mark Vajaranant (University of Illinois), Dr Indu Pathak and Dr Hamida Khakoo (Metropolitan Hospital Center), Dr Nancy Wade and Dr Renee Samelson (Children's Hospital at Albany Medical Center), Emily Barr and Dr John Nosovitch (State University of New York Upstate Medical University), Pam Daniel and Patty Kohler, RN (University of Cincinnati), Dr Margaret Keller and Marie Beall (Harbor University of California Medical Center), Angela Ranzini and Marian Lake (St Peter's Medical Center), Dr Robert Pass and Dr Marilyn Crain (University of Alabama), Dr Valerie Whiteman and Dr Ellen Tidaldi (Temple University School of Medicine), Carla Duff, RN and Dr John Sleasman (University of Florida, Gainesville), Dr Hector Cintron and Wanda Figueroa (Ramon 
Ruiz), Dr George Johnson and Moya Clarken, RN (Medical University of South Carolina), Dr Savita Pahwa (North Shore LIJ Research Institute), Dr Sunanda Gaur and Patricia Whitley Williams (Robert Wood Johnson AIDS Program), Dr Michael Hughes and Dr David Shapiro (Statistical and Data Analysis Center, Harvard School of Public Health). European Collaborative Study: Dr I. Grosch-Worner (Charite Virchow-Klinikum, Berlin, Germany), Dr J. Jimenez (Hospital 12 De Octubre, Madrid, Spain); Dr A.B. Bohlin, Dr S. Lindgren, (Huddinge and Karolinska Hospitals, Sweden), Dr A. Mur, Dr A. Paya, (Hospital del Mar, Barcelona, Spain), Dr O. Coll, Dr C. Fortuny (Hospital Clinic, Barcelona, Spain), Dr M. Casellas Caro (Hospital Vall D'Hebron, Barcelona, Spain), Dr M. Leyes, Dr L. Ciria (Hospital Son Dureta, Mallorca), Prof P. Martinelli, Dr W. Buffolano, DrM. Sansone (II Policlinico, Naples, Italy), Dr C. Tibaldi, Dr N. Ziarati (S Anna Hospital, Torino, Italy), Dr S. Alberico, Dr C. Salvatore (Burlo Garofolo Hospital, Trieste, Italy), Prof M. Temmerman (University of Ghent), Dr I. Hoesli, Dr C. Rudin (University of Basel), Dr X. Carnet, Dr J. Pich (Clinical Pharmacology Unit, University of Barcelona), Dr M. Ravizza, Prof G. Pardi, Dr L. Mangiarotti (San Paolo Hospital, Milan, Italy), Dr V. Savasi, Dr A.E. Semprini, Prof E. Ferrazzi (Sacco Hospital, Milan, Italy), Dr M. Sharland, Ms T. Chester, (St George's Hospital, London, UK), Dr A. Fakoya (Newham General Hospital, London, UK), Dr G. Scaravelli (PUI, Rome, Italy), Dr W. Coroleou, Dr Cavalle Gelabret (H Germans Trials Ipujol, Badalona, Spain), Prof C. Loveday (University College London, UK); France (ANRS 083 Trial group): Scientific Committee: Annie Metro (ANRS), Marie-Jeanne Mayaux, Stephane Blanche, Christine Rouzioux, Marc Tardieu (Enquete Pediatrique Francaise (EPF)); Jean-Pierre Aboulker (Service Commun I0, INSERM); Bertrand Baumelo (Boehringer Ingelheim, France); Clinicians: Veronique Chambrin, Hassina Razafimahefa (Hopital Antoine Beclere, Clamart), Laurent Mandelbrot, Guislaine Firtion (Hopital Cochin-Port Royal, Paris), Nicole Ciraru-Vigneron, Claudine Bruner (Hopital Lariboisiere, Paris), Alain Berrebi, Joelle Tricoire (Hopital Purpan, Toulouse), Claude Hocke, Daniele Douard (Hopital Pellegrin, Bordeaux), Catherine Crenn-Hebert, Corinne Floch-Tulal (Hopital Louis-Mourier, Colombes), Etienne Wilmer, Annick Ottenvalter (Hopital Robert Debre, Paris), Marie-Aude Khuong, Jean-Marc Retbi (Hopital Delafontaine, Saint-Denis), Vincent Jeantils, Eric Lachassine (Hopital Jean-Verdier, Bondy), Sophie Matheron, Jean-Louis Benifla (Hopital Bichat-Claude-Bernard, Paris), Cristianne Huraux-Rendu, Joelle Teboul (Hopital Henri-Mondor, Creteil), Deborah Fried, Brigitte Heller-Roussin (Hopital Intercommunal Montreuil), Brigitte Clavier, Veronique Brossard (Hopital Charles Nicolle, Rouen), Andre Bongain, Fabrice Monpoux (Hopital de l'Archet, Nice), Michel Levardon, Fabienne Mazy (Hopital Beaujon, Clichy), Veronique Cayol, Catherine Dolfus (Hopital Saint-Antoine-Trousseau, Paris), Paul Benos, Joelle Nicolas (Hopital Arnaud De Villeneuve, Montpellier), Daniel Raudrant, Laurent Cotte (Hopital de I'Hotel Dieu, Lyon), Cecile Francois, Francoise Mechinaud (Hopital de I'Hotel-Dieu, Nantes), Rose Nguyen, Adrien May (Hopital Louise Michel, Evry), Benedicte Mougeon, Alain Devidas (Hopital Gilles de Corbeil, Corbeil).

\section{References}

I. European Collaborative Study: Risk factors for mother-to-child transmission of HIV-I. Lancet 1992, vol. 339:1007-I0I2.

2. Blanche S, Rouzioux C, Moscato ML, Veber F, Mayaux MJ, Jacomet C, Tricoire J, Deville A, Vial M, Firtion G: A prospective study of infants born to women seropositive for human immunodeficiency virus type I. HIV Infection in Newborns French Collaborative Study Group. N Engl J Med 1989, 320:1643-1648.

3. Landesman SH, Kalish LA, Minkoff HL, Fox HE, Zorrilla C, Garcia PM, Fowler MG, Mofenson LM, Tuomala RE, The Women and Infants Transmission Study: Obstetrical factors and the transmission of human immunodeficiency virus type I from mother-tochild. N Eng J Med 1996, 334:1617-1623.

4. Dabis F, Msellati P, Dunn DT, Lepage P, Newell ML, Perre P, Working Group on Mother-to-Child Transmission of HIV: Estimating the rate of mother-to-child transmission of HIV. Report of a workshop on methodological issues, Ghent (Belgium), 17-20 February 1992. AIDS 1993, 7: I I39-II48.

5. Nair P, Alger L, Hines S, Seiden S, Hebel R, Johnson JP: Maternal and neonatal characteristics associated with HIV infection in infants of seropositive women. J Acquir Immune Defic Syndr 1993, 6:298-302.

6. Kind C, Brandle B, Wyler CA, Calame A, Rudin C, Schaad UB, Schupbach J, Senn HP, Perrin L, Matter L, The Swiss Neonatal HIV Study Group: Epidemiology of vertically transmitted HIV-I infection in Switzerland: results of a nationwide prospective study. Eur J Pediatr 1992, I 5 I:442-448.

7. Abrams EJ, Matheson PB, Thomas PA, Thea DM, Krasinski K, Lambert G, Shaffer N, Bamji M, Hutson DG, Grimm K, Kaur A, Rogers MF, New York City Perinatal HIV Transmission Collaborative Study Group: Neonatal predictors of infection status and early death among 332 infants at risk of HIV-I infection monitored prospectively from birth. Pediatrics 1995, 96:45I-458.

8. European Collaborative Study: The mother-to-child HIV transmission epidemic in Europe: evolving in the East and established in the West. AIDS 2006, 20:1419-1427.

9. Ryder RW, Behets F: Reasons for the wide variation in reported rates of mother-to-child transmission of HIV-I. AIDS I994, 8:1495-I 497

10. Cohen MH, Cook JA, Grey D, Young M, Hanau LH, Tien P, Levine AM, Wilson TE: Medically eligible women who do not use HAART: the importance of abuse, drug use, and race. Am J Public Health 2004, 94: I I47-I I II.

II. Hamers FF, Batter V, Downs AM, Alix J, Cazein F, Brunet JB: The HIV epidemic associated with injecting drug use in Europe: geographic and time trends. AIDS 1997, I I: I365-1374.

12. European Collaborative Study: Vertical transmission of HIV-I: maternal immune status and obstetric factors. AIDS 1996, 10:1675-1681.

13. Hamers FF, Downs AM: The changing face of the HIV epidemic in western Europe: what are the implications for public health policies? The Lancet 2004, 364:83-94.

14. Centers For Disease Control and Prevention: HIVIAIDS Surveillance in Women. Slide Series www cdc gov/hiv/graphics/women htm 2004, L264:

15. Dominguez KL, Lindegren ML, D'Almada PJ, Peters VB, Frederick T, Rakusan TA, Ortiz IR, Hsu HW, Melville SK, Sadek R, Fowler MG: Increasing Trend of Cesarean Deliveries in HIV-Infected Women in the United States From 1994 to 2000. J Acquir Immune Defic Syndr 2003, 33:232-238.

16. Centers For Disease Control and Prevention: Enhanced Perinatal Surveillance - United States, 1999-200I 4th edition. Atlanta, US Department of Health and Human Sciences; 2004: I-22.

17. Gebo KA, Fleishman JA, Conviser R, Reilly ED, Korthuis PT, Moore RD, Hellinger J, Keiser P, Rubin HR, Crane L, Hellinger FJ, Mathews WC, Network HIVR: Racial and gender disparities in receipt of highly active antiretroviral therapy persist in multstate sample of HIV patients in 200I. J Acquir Immune Defic Syndr 2005, 38:96-103.

18. Palacio H, Kahn JG, Richards TA, Morin SF: Effect of race and/or ethnicity in use of antiretrovirals and prophylaxis for opportunistic infection: a review of the literature. Public Health Rep 2002, I I 7:233-25I.

19. European Collaborative Study: Therapeutic and other interventions to reduce the risk of mother-to-child transmission of HIV-I in Europe. Br J Obstet Gynaecol 1998, I05:704-709.

20. Dorenbaum A, Cunningham CK, Gelber RD, Culnane M, Mofenson LM, Britto P, Rekacewicz C, Newell ML, Delfraissy JF, CunninghamSchrader B, Mirochnick M, Sullivan JL, Team IPACTG: Two-dose intrapartum/newborn nevirapine and standard antiretroviral therapy to reduce perinatal HIV transmission. A randomised trial. JAMA 2002, 288: 189-198.

21. Fiore S, Thorne C, Newell ML: European involvement in an international perinatal trial. Developmental Period Medicine 2003, 7:449-458.

22. Connor EM, Sperling RS, Gelber RD, Kiselev P, Scott GB, O'Sullivan MJ, Van Dyke R, Bey M, Shearer WT, Jacobson RL, Jimenez E, O'Neill E, Bazin B, Delfraissy JF, Culnane M, Coombs RW, Elkins MM, Moye JJ, Stratton P, Balsey J: Reduction of maternal-infant transmission of human immunodeficiency virus type I with zidovudine treatment. N Eng J Med 1994, 33 I: | | 173-। | 80. 
23. Hamers FF, Infuso A, Alix J, Downs AM: Current situation and regional perspective on HIVIAIDS surveillance in Europe. J Acquir Immune Defic Syndr 2003, 32:S39-S48.

24. Mosher WD, Bachrach CA: Understanding U.S. fertility: continuity and change in the National Survey of Family Growth, 1988-1 995. Fam Plann Perspect 1996, 28:4-12.

25. The CAESAR Coordinating Committee: Randomised trial of addition of lamivudine or lamivudine plus loviride to zidovudinecontaining regimens for patients with HIV-I infection: the CAESAR trial. Lancet 1997, 349:|4|3-|42I.

26. Carpenter CCJ, Fischl MA, Hammer SM, Hirsch MS, Jacobsen DM, Katzenstein DA, Montaner JSG, Richman DD, Saag MS, Schooley RT, Thompson MA, Vella S, Volberding PA: Antiretroviral therapy for HIV infection in 1997: updated recommendations of the International AIDS Society-USA panel. JAMA 1997, 277:1962-1969.

27. Cooper ER, Charurat M, Mofenson LM, Hanson IC, Pitt J, Diaz C, Hayani K, Handelsman E, Smeriglio V, Hoff R, Blattner WA: Combination antiretroviral strategies for the treatment of pregnant HIV-I-infected women and prevention of perinata HIV-I transmission. J Acquir Immune Defic Syndr 2002, 29:484-494.

28. European Collaborative Study: HIV-infected pregnant women and vertical transmission in Europe since 1986. AIDS 200I, 15:76|-770.

29. Mandelbrot L, Le Chenadec J, Berrebi A, Bongain A, Benifla JL, Delfraissy JF, Blanche S, Mayaux MJ, Cohort FP: Perinatal HIV-I Transmission - Interaction Between Zidovudine Prophylaxis and Mode of Delivery in the French Perinatal Cohort. JAMA 1998, 280:55-60.

30. European Collaborative Study: Pregnancy-related changes in the longer-term management of HIV infected women in Europe. Eur J Obstet Gynecol Reprod Biol 2003, I I I:3-8.

31. The Italian Register for HIV Infection in Children: Determinants of mother-to-infant human immunodeficiency virus I transmission before and after the introduction of zidovudine prophylaxis. Arch Pediatr Adolesc Med 2002, I 56:915-92I.

32. European Collaborative Study: Mother-to-child transmission of HIV Infection in the era of highly active antiretroviral therapy. Clin Infect Dis 2005, 40:458-465.

33. Warszawski J, Tubiana R, Le Chenadec J, Blanche S, Teglas JP, al : Is intrapartum intravenous zidovudine still beneficial to prevent mother-to-child HIV-I transmission? 12th Conference on Retroviruses and Opportunistic Infections, 22-25 February 2005, Boston, USA 2005, Abstract:78I.

34. Mandelbrot L, Landreau A, Rekacewicz C, Berrebi A, Benifla JL, Burgard $M$, Lachassine $E$, Chaix ML, Bongain $A$, Ciraru-Vigneron $N$, Crenn-Herbert C, Delfraissy JF, Rouzioux C, Mayaux MJ, Blanche S, the Agence Nationale de Recherches sur le SIDA ANRSG: Lamivudine-Zidovudine Combination for Prevention of MaternalInfant Transmission of HIV-I. JAMA 200I, 285:2083-2093.

35. Cunningham CK, Balasubramanian R, Delke I, Maupin R, Mofenson L, Dorenbaum A, Sullivan JL, Gonzalez-Garcia A, Thorpe E, Rathore M, Gelber RD: The impact of race/ethnicity on mother-to-child HIV transmission in the United States in Pediatric AIDS Clinical Trials Group Protocol 316. J Acquir Immune Defic Syndr 2004, 36:800-807.

36. Fiscus SA, Adimora AA, Funk ML, Schoenbach VJ, Tristram D, Lim W, McKinney RE, Rupar D, Woods C, Wilfert C: Trends in interventions to reduce perinatal human immunodeficiency virus type I transmission in North Carolina. Pediatr Infect Dis J 2002, 2I:664-668.

37. Stringer JSA, Rouse DJ, Goldenberg RL: Prophylactic cesarean delivery for the prevention of perinatal human immunodeficiency virus transmission. The case for restraint. JAMA 1999, 28 I: 1946-1949.

38. Brockmeyer N: German-Austrian Guidelines for HIV-therapy during pregnancy--status: May/June 1998--common statement of the Deutsche AIDS-Gesellschaft (DAIG) and the Osterreichische AIDS-Gesellschaft (OAG). Eur J Med Res I999, 4:35-42.

39. Taylor GP, Lyall EGH, Mercey D, Smith JR, Chester T, Newell ML, Tudor-Williams G: British HIV Association guidelines for prescribing antiretroviral therapy in pregnancy (1998). Sexually Transmitted Infections 1999, 75:90-97.

40. Newell ML, Rogers MF: Pregnancy and HIV infection: a European Consensus on management. AIDS 2002, 16:SI-SI8.
4I. British HIV Association: Guidelines for the management of HIV infection in pregnant women and the prevention of mother-to-child transmission of HIV London, British HIV Association; 2005:www.bhiva.org.

42. Hankins C, Lapointe N, Walmsley S: Participation in clinical trials among women living with HIV in Canada. Canadian Women's HIV Study Group. CMA] 1998, I59:1359-1365.

43. Gandhi M, Ameli N, Bacchetti P, Sharp GB, French AL, Young M, Gange SJ, Anastos K, Holman S, Levine A, Greenblatt RM: Eligibility criteria for HIV clinical trials and generalizability of results: the gap between published reports and study protocols. AIDS 2005, 19: 1885-1896.

44. Moore DAJ, Goodall RL, Ives NJ, Hooker M, Gazzard BG, Easterbrook PJ: How generalizable are the results of large randomized controlled trials of antiretroviral therapy? HIV Medicine 2000, I:I49-I54.

\section{Pre-publication history}

The pre-publication history for this paper can be accessed here:

http://www.biomedcentral.com/1471-2334/7/60/prepub
Publish with Biomed Central and every scientist can read your work free of charge

"BioMed Central will be the most significant development for disseminating the results of biomedical research in our lifetime. "

Sir Paul Nurse, Cancer Research UK

Your research papers will be:

- available free of charge to the entire biomedical community

- peer reviewed and published immediately upon acceptance

- cited in PubMed and archived on PubMed Central

- yours - you keep the copyright
BioMedcentral 